Check for updates

1 Department of Radiology, Royal Free Hospital NHS Trust, London, UK

2 Royal Free Hospital NHS Trust, London, UK

3 UCL Medical School, Royal Free Campus, London, UK

4 Research Department of Primary Care \& Population Health, UCL, Royal Free Campus, London, UK

5 Institute of Biomedical Education, St George's University of London, London, UK

Correspondence to M Jones melvyn.jones@ucl.ac.uk Cite this as: BMJ2020;370:m2426 http://dx.doi.org/10.1136/bmj.m2426 Published: 16 July 2020

PRACTICE POINTER

\title{
The role of chest radiography in confirming covid-19 pneumonia
}

Joanne Cleverley, ${ }^{1}$ James Piper, ${ }^{2,3}$ Melvyn M Jones ${ }^{4,5}$

What you need to know

- A normal chest radiograph does not exclude covid-19 pneumonia

- No single feature of covid-19 pneumonia on a chest radiograph is specific or diagnostic, but a combination of multifocal peripheral lung changes of ground glass opacity and/or consolidation, which are most commonly bilateral, may be present

- Diagnosis might be complicated as covid-19 pneumonia may or may not be visible on chest radiograph; consider other causes for patients' respiratory symptoms

Covid-19 is likely to remain an important differential diagnosis for the foreseeable future in anyone presenting to hospital with a flu-like illness, lymphopenia on full blood count, and/or a change in normal sense of smell (anosmia) or taste. ${ }^{12}$

Most people with covid-19 infection do not develop pneumonia ${ }^{3}$; however, chest radiography of people who are seriously ill with respiratory symptoms when they present to hospital can help to identify those with covid-19 pneumonia.

In this article we offer advice to non-radiologists on how to look for changes on chest radiograph that may be suggestive of covid-19 pneumonia, as prompt review and report from an onsite or remote radiologist is not always available.
The recommendations in this article are based on a combination of emerging evidence, current guidelines, and our clinical experience.

For the radiograph examples used in this article, we cannot confirm whether each patient tested positive for covid-19 because we did not have access or ethical approval to access these patients' clinical records; however, they were all diagnosed with covid-19 pneumonia as they had supportive radiographical features during the covid-19 pandemic.

\section{What is covid-19 pneumonia?}

No fixed definition of covid-19 pneumonia exists; in this article the term is used when describing patients with clinical features of covid-19 infection who have either clinical or radiological evidence of pneumonia, ${ }^{45}$ or acute respiratory distress. ${ }^{1}$

Like other pneumonias, covid-19 pneumonia causes the density of the lungs to increase. This may be seen as whiteness in the lungs on radiography which, depending on the severity of the pneumonia, obscures the lung markings that are normally seen; however, this may be delayed in appearing or absent.

- When lung markings are partially obscured by the increased whiteness, a ground glass pattern (ground glass opacity, fig 1) occurs. This can be subtle and might need confirmation with a radiologist. 


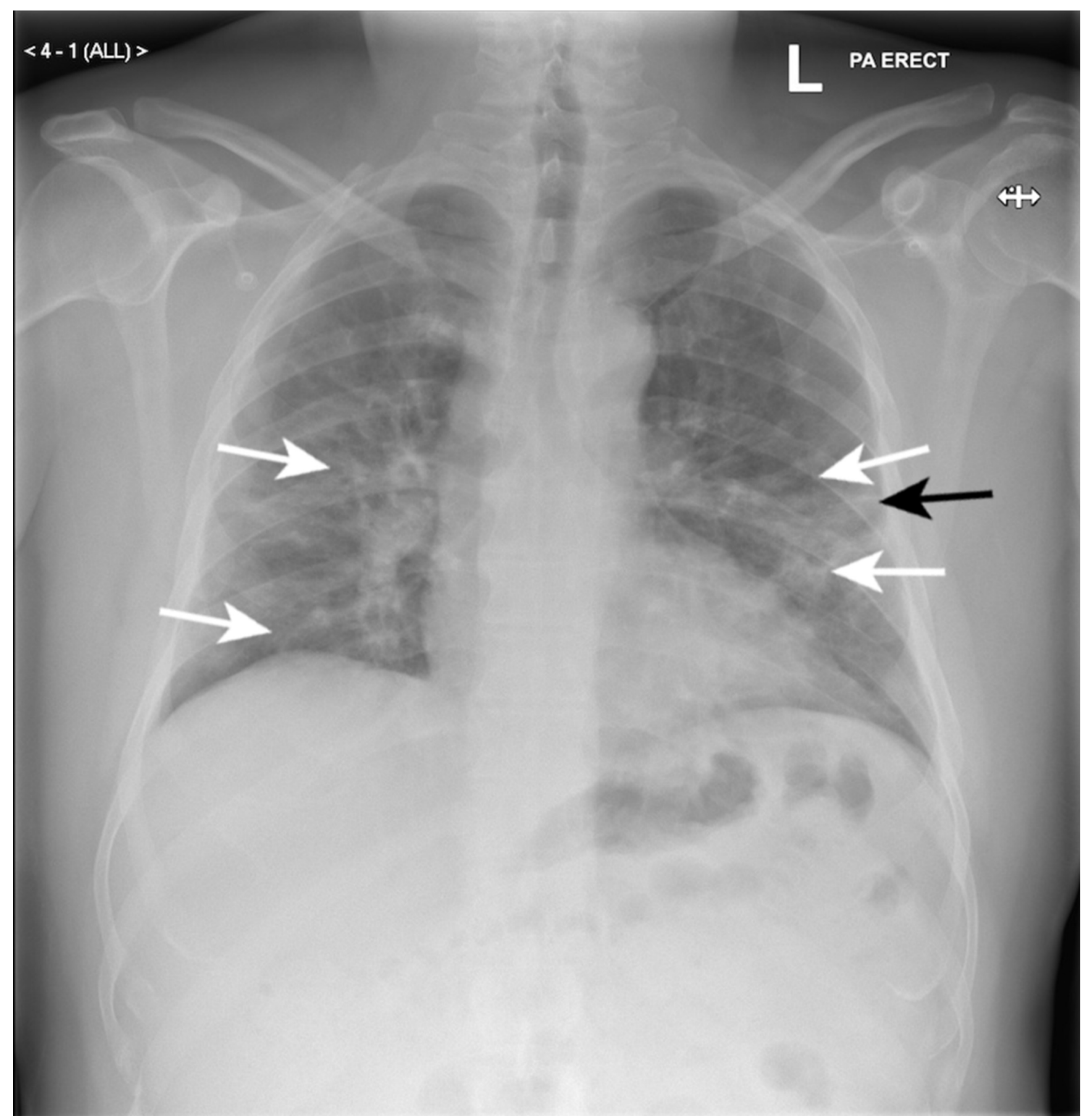

Fig 1 | Ground glass opacity. Posterior-anterior chest radiograph of patient A, a man in his 50s with covid-19 pneumonia. Features include ground glass opacity in both mid and lower zones of the lungs, which is predominantly peripheral (white arrows) with preservation of lung marking. Linear opacity can be seen in the periphery of the left mid zone (black arrow)

- Peripheral, coarse, horizontal white lines, bands, or reticular changes which can be described, as linear opacities may also be seen in association with ground glass opacity (fig 1).

- When lung markings are completely lost due to the whiteness, it is known as consolidation (this is usually seen in severe disease) (fig 2, 3c). ${ }^{6} \mathrm{~A}$ small case series in Korea found that, in polymerase chain reaction (PCR) confirmed covid-19 infection, in those with radiological abnormalities, $70 \%$ of the radiographical opacities (number of lesions, not patients) were consolidation. ${ }^{7}$ 


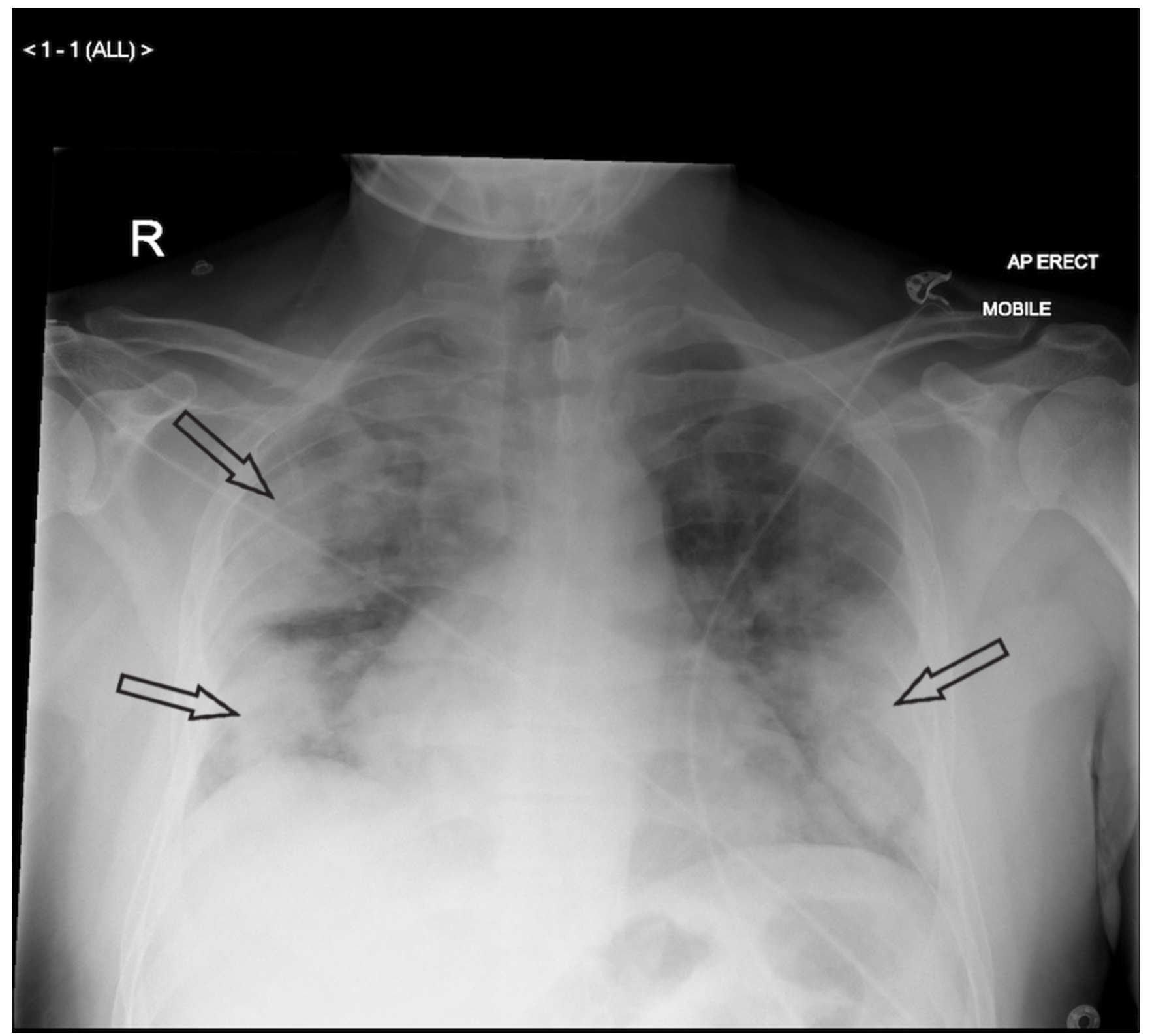

Fig 2 | Consolidation. Anterior-posterior (AP) chest radiograph of patient B, a man in his 50s, with severe covid-19 pneumonia, showing bilateral dense peripheral consolidation and loss of lung markings in the mid and lower zones (outlined arrows) 

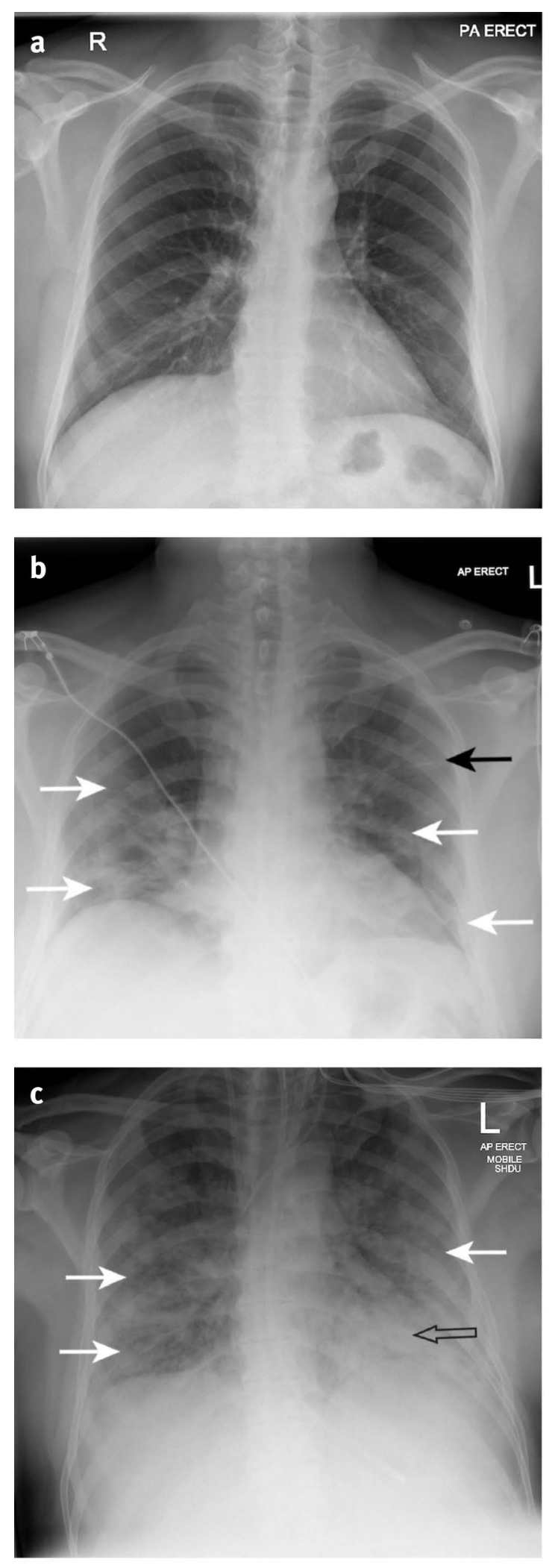

Fig 3 | Serial radiological progression seen with covid-19 pneumonia. (a) Normal posterior-anterior chest radiograph of patient C, a man in his 50 s (taken up to 12 months before admission, included here for comparison). (b) AP chest radiograph of patient $\mathrm{C}$ when he developed covid-19 pneumonia-taken in the emergency department (day 0 of admission), showing ground glass opacities in the periphery (outer third of the lung) of both lungs in the mid and lower zones (white arrows), preservation of lung marking, and linear opacity in the periphery of the left mid zone (black arrow). (c) AP chest radiograph of patient $\mathrm{C}$ on day 10 of admission, showing progression to severe covid-19 pneumonia: patient intubated with endotracheal tube, central lines, and nasogastric tube in situ. Dense consolidation with loss of lung markings is now seen behind 
the heart in the left lower zone (outlined arrow). Extension of the peripheral ground glass changes seen in (b) can be seen in the periphery of the right mid and lower zones and the left mid zone (white arrows)

Covid-19 pneumonia can be classed as an atypical pneumonia because of the radiographic appearances of multifocal ground glass opacity, linear opacities, and consolidation. These changes are also seen in other atypical pneumonias, including other coronavirus infections (severe acute respiratory system, SARS, and Middle East respiratory syndrome, MERS). ${ }^{8}$

\section{What do you look for on chest radiography?}

Review the radiograph systematically, looking for abnormalities of the heart, mediastinum, lungs, diaphragm, and ribs, ${ }^{9}$ and remembering that radiographic changes of covid-19 pneumonia can be subtle or absent.

Compare with previous chest radiographs when available.

Look for evidence of ground glass opacity, peripheral linear opacities, or consolidation in the lung.

\section{Which parts of the lungs are usually affected?}

A quantitative meta-analysis covering 2847 patients in China and Australia, and a multinational descriptive analysis of 39 case report articles summarising 127 patients, found that covid-19 pneumonia changes are mostly bilateral on chest radiographs $(72.9 \%, 95 \%$ confidence interval 58.6 to 87.1 ) and have ground glass opacity in $68.5 \%$ of cases ( $95 \% \mathrm{CI} 51.8$ to 85.2 ) (fig 1, fig 3b); however, these data are pooled so it is not possible to link the radiographic findings to the duration of disease or severity. ${ }^{10}$

A retrospective case series of 64 patients hospitalised with covid-19 infection in Hong Kong found that chest radiograph changes are often peripheral $(41 \%)$ and lower zone $(50 \%)$ in distribution ${ }^{11}$; these findings are supported by a pictorial review from the US describing common manifestations and patterns of lung abnormality seen on portable chest radiography in covid-19 patient ${ }^{12}$; it does not, however, describe a formal methodology, the geographical location of the patients, or the numbers of patients included.

This pictorial review also suggests that the coarse linear opacities associated with covid-19 on chest radiography typically appear in the lung peripheries (fig 1 , fig 3 b). ${ }^{12}$

A small case series in Korea showed that $80 \%$ of radiographical changes (again this relates to the number of radiological lesions seen, not patients) were found peripherally. ${ }^{7}$

Summary of potential chest radiograph findings in covid-19 pneumonia

- Most patients with covid-19 infection have a mild illness and do not develop pneumonia ${ }^{3}$

- The chest radiograph may be normal in up to $63 \%$ of people with covid-19 pneumonia, particularly in the early stages 7111625 (but there is uncertainty around this estimate, ranging from $0 \%$ to $63 \%$ )

- Changes include ground glass (68.5\%), ${ }^{10}$ coarse horizontal linear opacities, and consolidation. ${ }^{12}$ These are more likely to be peripheral and in the lower zones, but the whole lung can be involved ${ }^{11}$

- Ground glass appearance is common in earlier presentations and may precede the appearance of consolidation ${ }^{11} 12$

- Bilateral lung involvement is most common (72.9\%) (but can be unilateral in $25 \%) .{ }^{10}$
- Signs suggestive of potential comorbidities on chest radiography might be obscured by signs of covid-19 pneumonia

- The appearance of nodules, pneumothorax, or pleural effusion (1-3\%) might be incidental, caused by covid-19 or by comorbidities

\section{What else might be visible?}

Consider covid-19 infection in patients with nodular lung lesions, pneumothorax, and pleural effusion as these have been reported in case series of patients with covid-19 infection in China and Korea $^{7111^{14}}$; however, the evidence within these reports is not strong, making it difficult to be certain when these are incidental findings, a sign of dual pathology, or unusual manifestations of covid-19. The pictorial review mentioned above also reports this range of radiological abnormalities but cites similar studies. ${ }^{12}$

Look for cardiac outline abnormalities on chest radiography as cardiac complications are reported with covid-19 (which can be seen on echo ${ }^{15}$ ); however, no reports of cardiac abnormalities seen on chest radiographs have been published.

It is good practice to look for radiograph features that might indicate comorbidities such as tumours, emphysema, community acquired pneumonia, and bone fracture. Look for misplaced tubes (eg, endotracheal, nasogastric, pleural drains) and lines (eg, central venous lines), and evidence of heart disease including sternotomy wires, which could indicate previous cardiac surgery. Not all of these comorbidities have been reported in relation to covid-19 chest radiographs ${ }^{1016-18}$; however, in some cases, covid-19 pneumonia changes might be so widespread that features suggestive of comorbidities are obscured.

\section{What are the differential diagnoses?}

Ground glass appearance, consolidation, and linear opacities can also be caused by

- Other atypical pneumonias and the early stages of community acquired pneumonias

- Pulmonary aspiration

- Pulmonary oedema

- Lung cancer

- Inflammatory lung disease, such as pulmonary eosinophilia

- Vasculitides, eg Wegener's (granulomatosis with polyangiitis)

- Haemorrhage.

Causes of other atypical pneumonias include SARS and MERS, mycoplasma infection, Coxiella burnetti, and legionella ${ }^{19}$ (not an exclusive list).

Causes of bacterial community acquired pneumonias include Streptococcus pneumoniae, Haemophilus influenzae, and Klebsiella ${ }^{20}$ (not an exclusive list). Chest radiograph changes from community acquired pneumonias are typically unilateral affecting only one part of the lung. Community acquired pneumonias are predominantly associated with consolidation on chest radiography, not ground glass opacity or linear opacities. ${ }^{20}$ 
Recent reports suggest that vaping causes radiological abnormalities, ${ }^{21}$ and these appearances have been described as being similar to covid-19.

\section{How reliable is chest radiography?}

Avoid relying solely on imaging findings; use them in conjunction with clinical findings to form an overall clinical assessment, because

- No single feature on chest radiography is diagnostic of covid-19 pneumonia

- Initial chest radiography may be normal but patients may later develop clinical or radiological signs of covid-19 pneumonia-ie, early radiographs may be negative (see patient $\mathrm{D}$, fig 4$)^{1122} 23$

\footnotetext{
- A retrospective case series of 64 patients hospitalised with covid-19 infection in Hong Kong found that 31\% (20 patients) had normal chest radiographs on admission. Of these patients, $35 \%(\mathrm{n}=7)$ developed radiographical changes on follow-up radiography. ${ }^{11} 22$ This study also suggested that peak radiological severity on chest radiography is seen at days 10-12 of symptom onset. ${ }^{11}$ (see patient C, fig 3 )
}

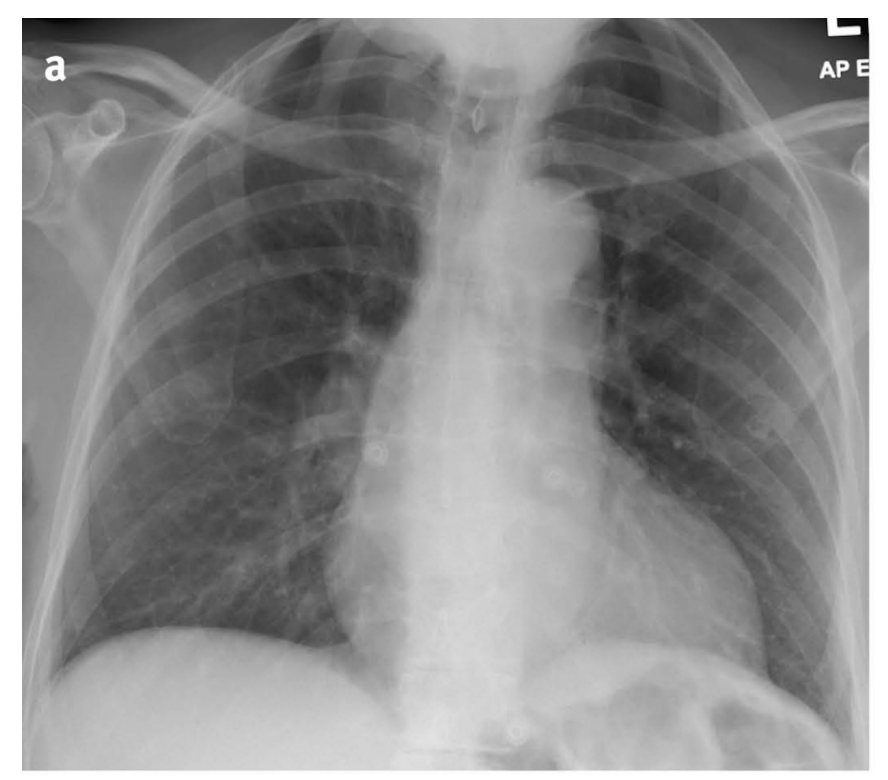

- On the basis of this study, the multinational consensus statement from the Fleischner Society for thoracic radiology stated that chest radiography can be insensitive in mild or early covid-19 infection. ${ }^{22} 24$

- In a series of 1099 hospitalised patients with laboratory confirmed covid-19 from across China, of the 274 patients who had chest radiography on admission 162 (59.1\%) showed abnormalities, most commonly "bilateral patchy shadowing" $(\mathrm{n}=100,36.5 \%)$. Of 1099 patients 975 had computed tomography but it is unclear how many of the chest radiographs were false negatives for covid pneumonia.

- The introduction of a systematic review of case series and case reports covering 919 patients in China and Korea suggests that while chest radiography is of little diagnostic value in the early stages, in intermediate and advanced stages, features suggestive of covid-19 infection may be seen. ${ }^{23}$ However, it is unclear in the review how the conclusions regarding chest radiography were reached.

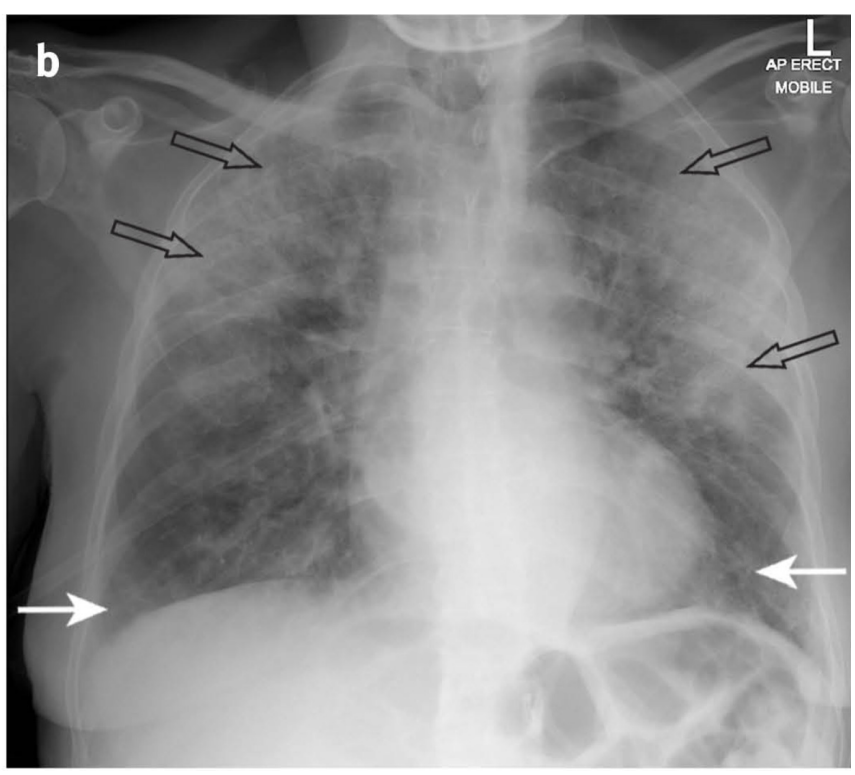

Fig 4 | Serial radiological progression seen with covid 19 pneumonia . (a) A normal AP chest radiograph of patient D, a woman in her 70s who is in hospital with covid-19 infection (day 0 of admission). (b) An AP chest radiograph of patient D on day 8, showing ground glass opacification now present at both lung bases (white arrows). Consolidation is also seen in the periphery of the left upper and mid zones (outlined arrows). Increased density (whiteness) is also present in the periphery of the right upper zone; this is not as dense or white as that seen in the left lung, showing progression of lung change of ground-glass opacification to consolidation (outlined arrows)

A case series of 799 patients from Wuhan China with confirmed covid-19 looked at a subset of those who died $(n=113)$ or were discharged $(\mathrm{n}=161)$ and reported that all patients had abnormalities on chest radiograph on admission. ${ }^{16}$

- Chest radiographs can be normal in some patients with clinically diagnosed covid-19 pneumonia, or who have been diagnosed with covid-19 pneumonia by computed tomography-ie, there may be false negative radiographs. ${ }^{71125}$

- In the Hong Kong retrospective case series described above, four patients never developed abnormalities on radiography; however one of these patients $(25 \%)$ had ground glass opacities on chest computed tomography (performed within 48 hours of chest radiography). ${ }^{11}$
- A case series of nine patients with PCR confirmed covid-19 infection in Korea reported that three had abnormal baseline radiographs but eight had changes on baseline computed tomography, suggesting five of eight baseline radiographs $(63 \%)$ were false negatives. ${ }^{7}$

- A case series in China reported that a subset of two of five (40\%) patients had normal chest radiographs, but computed tomography done on the same day confirmed covid-19 pneumonia. ${ }^{25}$

Features and limitations of chest radiographs in covid-19

\section{Normal}

- Central mediastinum and heart appear normal 
- Lungs predominantly contain air (appearing black)

- Lung markings are present, representing blood vessels extending from the hilum to the lung periphery (these branch and decrease in calibre, such that few vessels are seen at the lung periphery)

- The diaphragm is curvilinear in outline with sharp costophrenic margins

\section{Ground glass opacity}

- The initial abnormalities suggesting covid-19 pneumonia on a chest radiograph are loss of the normal black appearance in the lung

- This is seen as increased whiteness, (because of increased density), but not enough to totally obscure lung markings; giving a ground glass appearance

- Ground glass opacities can be difficult to observe; radiologist confirmation is recommended

- Horizontal linear opacities may be seen with ground-glass change ${ }^{9}$ (fig 1, fig 3b)

- Location: usually bilateral but can be unilateral. ${ }^{7}$ More often reported in a peripheral lung8 adjacent to the chest wall and diaphragm and usually with a distribution in the mid and lower zones ${ }^{8} 9{ }^{11} \mathrm{Fig} 4 \mathrm{~b}$ shows ground glass opacities in the right upper zone, as will be the case in approximately $20 \%$ of patients with covid- 19 pneumonia

\section{Consolidation}

- Ground-glass opacities become denser (whiter) and progress to consolidation with complete loss of lung markings
- Location: The areas of consolidation are likely to have progressed from sites of ground glass opacities (fig 2, fig $3 \mathrm{c}$ )

\section{Limitations}

AP images from portable machines produce a poorer quality image when compared with a PA chest radiograph done in a dedicated radiography facility, therefore can be more difficult to interpret. Limitations of AP chest radiograph include reduced inspiratory effort because of the patient's positioning (potentially exacerbated by their illness), resulting in sub-optimal imaging; lung changes may therefore appear more marked or localised infection may be missed; the heart can also appear magnified. Under-exposure of a chest radiograph can occur with operator factors such inappropriate radiation dose, rotation of the patient, patient factors such high body mass index, chest wall abnormalities (or breast prostheses), and inappropriate processing of the image. In an under-exposed image, the whole radiograph appears whiter. In comparison with a site with pathology or abnormality, the affected site or area will be of increased density (whiter) compared with normal areas (fig 1)

\section{When and how is chest radiography requested?}

The British Society of Thoracic Imaging (BSTI) suggests that all seriously ill patients (oxygen saturation $<94 \%$, National Early Warning Score, NEWS $>3^{26}$ ) initially have a chest radiograph and that those who do not meet those criteria should have a chest radiograph if "clinically required" (fig 5). ${ }^{27}$

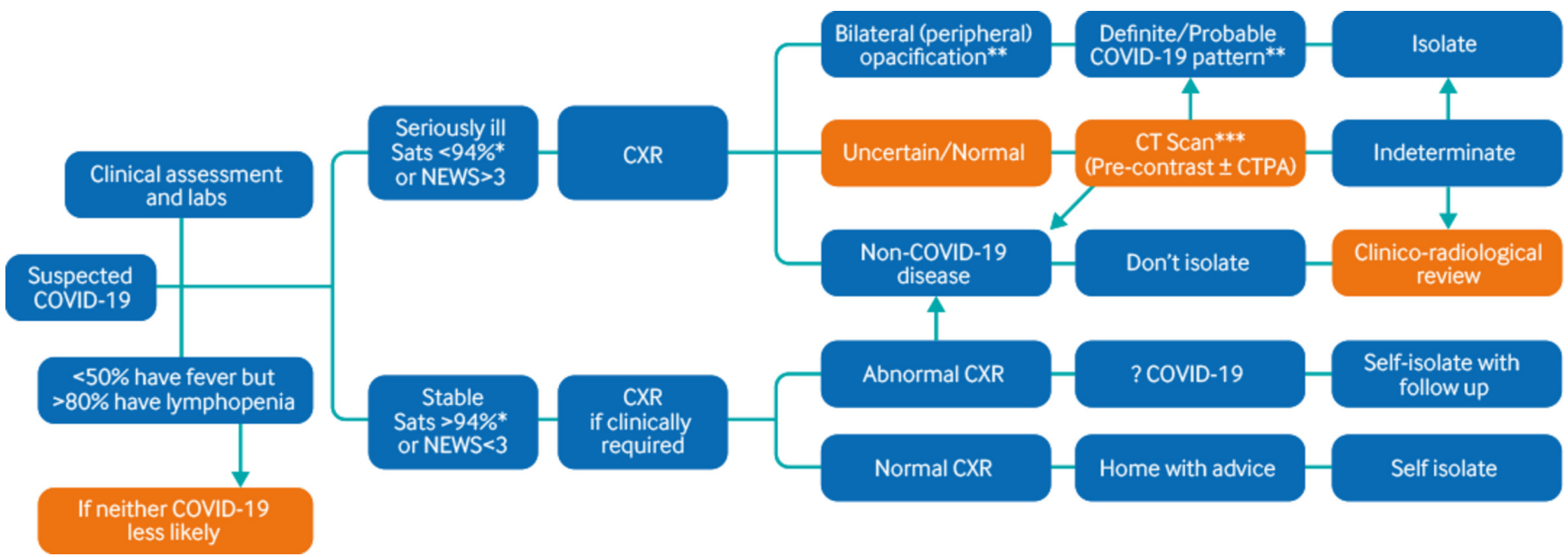

Fig 5 | Decision tool for radiological management of patients with suspected covid-19. Adapted from BSTI ${ }^{27} * 94 \%$ unless known COPD, in which case $<90 \%$ **Unsuspected/unexpected cases may be incidentally discovered on chest radiography/computed tomography at this stage; should be reviewed in the context of clinical suspicion as to likelihood of covid-19 ${ }^{\star \star \star}$ Classic and indeterminate computed tomography can be scored by the reporting radiologist for severity of findings as either "mild" or "moderate/severe"

Guidelines from the Fleischner Society for thoracic radiology recommend considering chest radiography and covid-19 testing (dependent on local availability) when inpatients have marked respiratory symptoms, which they define as "hypoxaemia, moderate-to-severe dyspnoea," after considering appropriate differential diagnoses. ${ }^{22} 28$

At our centre, in line with National Institute for Health and Care Excellence (NICE) guidance, ${ }^{29}$ all patients with marked respiratory symptoms caused by suspected covid-19 infection have a chest radiograph as a part of their initial assessment. Our local guidance involves seeing patients once referred ${ }^{30}$ with a threshold for investigating of any combination of fever $>37.8^{\circ} \mathrm{C}$; shortness of breath, especially at rest; persistent cough; new wheezing; respiratory rate $>20$ breaths $/ \mathrm{min}$; heart rate $>100$ beats $/ \mathrm{min}$; new confusion; haemoptysis; the appearance of cyanosis and oxygen saturations $<92 \% .{ }^{29}$

Make a note of known comorbidities and smoking history on paperwork requesting investigations; this will help radiologists to consider other pathologies that may be causing patients' symptoms.

Request posterior-anterior chest radiograph views whenever possible, as it produces a better image than an anterior-posterior image, although you may be guided by the patient's condition and local guidelines.

There is currently no role for requesting imaging for suspected covid-19 in UK primary care. 


\section{When might other radiological investigations be required?}

If the patient is breathless, with oxygen saturation of less than $94 \%$, and the chest radiograph is normal or uncertain for covid-19, BSTI guidelines advise chest computed tomography ${ }^{31}$ (fig 5).

Consider pulmonary emboli as a cause of respiratory symptoms as evidence suggests a high prevalence of thrombotic complications in covid-19 patients in intensive care. In a Dutch case series, of 184 patients in intensive care with covid-19 pneumonia, 31\% experienced thrombotic complication (composite outcome of symptomatic acute pulmonary embolism, deep vein thrombosis, ischaemic stroke, myocardial infarction, or systemic arterial embolism). ${ }^{32}$ Consider computed tomography pulmonary angiogram and relevant biochemical tests if pulmonary embolism is suspected.

\section{How does practice vary internationally?}

The BSTI ${ }^{31}$ states that there is "no role for computed tomography imaging in the diagnosis of covid-19 unless the patient is seriously ill (NEWS score >3) OR if PCR is unavailable" and the American Society of Thoracic Radiology (STR) 33 says "routine screening computed tomography for the identification of covid-19 pneumonia is currently not recommended by most radiology societies.” The Fleischner Society for thoracic radiology endorses this approach. ${ }^{22}$

In China, computed tomography has been preferred over chest radiography because patients were encouraged to present to hospital early for diagnosis as a public health measure, and computed tomography in the early stages of covid-19 infection is more likely to be diagnostic than early chest radiograph. ${ }^{22}$

In the US and UK, however, patients with early disease are encouraged to stay at home and to present to hospital only if symptoms progress; at this later stage the chance of detecting covid-19 changes on chest radiography is likely to be higher. ${ }^{22}$

Other countries, including Italy and Spain, have not reported their approach to covid-19 imaging beyond occasional case series and reports. ${ }^{34-36}$

In low resource settings, chest radiography may be more readily available than computed tomography. ${ }^{37}$

\section{How can cross infection risk be minimised?}

Minimise the risk of cross infection by considering whether imaging is necessary, and if so, which type of imaging is most appropriate. ${ }^{22}$ For example, with ventilated patients, a portable chest radiograph at the bedside has a lower risk of cross infection than computed tomography because ventilated patients are more likely to generate aerosol and will require additional support during imaging. To minimise cross infection risk from moving patients, some centres insist that only anterior-posterior chest radiographs (usually bedside) are performed. ${ }^{22}$

- Designate imaging areas as "non-covid-19” and “covid-19" areas with designated machines and decontamination procedures for patients with suspected covid-19. 3839

- Use appropriate personal protective equipment.

\section{Which patients need follow-up radiography?}

Guidance from the British Thoracic Society (BTS) recommends follow-up for patients with a clinico-radiological diagnosis of covid-19 pneumonia, as follows:

- Patients who required intensive care or high dependency unit admission or were cared for on the ward with severe pneumonia:
- Virtually assess at 4-6 weeks after hospital discharge, and proceed to face-to-face clinical assessment if indicated and a face-to-face review with chest radiography for all at approximately 12 weeks.

- Patients with a mild to moderate clinico-radiological diagnosis of covid-19 pneumonia who did not require intensive care or high dependency unit care-typically cared for on the ward or in the community:

- Request a routine follow-up chest radiograph at 12 weeks after discharge with different treatment pathways depending on radiographic resolution or not

The guidance recognises the clinical uncertainty about covid-19 pneumonia prognosis. We recommend that clinicians involved in such care read the full guidance. ${ }^{40}$

\section{Education into practice}

- How might the stage of a patient's illness affect chest radiograph interpretation?

- What differential diagnoses will you consider if consolidation is visible on chest radiography?

- What pathways are in place to ensure people who have had covid-19 pneumonia get the necessary follow-up?

\section{How patients were involved in the creation of this article}

$\overline{\text { Two patients reviewed this article. As a result of their input we have made }}$ several changes to the manuscript, including adding a clearer explanation of the differing approaches to imaging in the US, UK, and China, and including a reference to emerging information on cardiac complications of covid-19. They also helped identify acronyms and abbreviations that were very UK focused.

\section{Search strategy}

We searched PUBMED on the 26 March 2020 using the search terms "COVID-19," and "chest radiography." We identified 20 articles. We excluded articles about computed tomography or that were not related to imaging. Only in one article on screening did the title relate to chest radiographs. ${ }^{7}$

\section{How this article was made}

We searched Medline (see search strategy) and identified two relevant systematic reviews. We also used evolving local clinical guidance, Google scholar, and the NHS 111 website to collect current information on covid-19. JC used her expertise as a chest radiologist, seeing approximately 200 images of suspected covid-19 to inform this article. $\mathrm{JP}$ is an acute physician involved in the management of covid-19 patients. Most of the published research relates to China so we have supplemented this with local guidance where available.

Competing interests The BM/ has judged that there are no disqualifying financial ties to commercial companies. The authors declare the following other interests: none.

Further details of The BMJ policy on financial interests are here: https://www.bmj.com/about-bmj/resources-authors/forms-policies-and-checklists/declaration-competing-interests

Contributorship and guarantor: MJ conceptualised this article, undertook the literature search and is guarantor. JC used her knowledge of chest radiology to inform the content of the article and sourced the images. JP used his knowledge of assessment and management of covid-19 patients to inform the article. MJ, JC, and JP drafted and checked the final article.

Patient consent: We considered seeking individual consent to use radiological images. However, as patients with covid-19 are ill and an infectious risk, obtaining consent was not possible. We approached the hospital ethics committee chair, Trust R\&D, and Data Protection lead for permission to use anonymised radiological images without specific consent. They agreed this was acceptable. 
Provenance and peer review: commissioned; externally peer reviewed.

$1 \quad$ NHS England. Coronavirus: patient assessment. https://www.england.nhs.uk/coronavirus/secondary-care/assessment-diagnosis/patient-assessment/

2 Zhao Q, Meng M, Kumar R, etal. Lymphopenia is associated with severe coronavirus disease 2019 (COVID-19) infections: A systemic review and meta-analysis. Int I Infect Dis 2020;96:131-5. doi: 10.1016/j.jijid.2020.04.086 pmid: 32376308

3 Wu Z, McGoogan JM. Characteristics of and important lessons from the coronavirus disease 2019 (COVID-19) outbreak in China: summary of a report of 72314 cases from the Chinese Center for Disease Control and Prevention. JAMA 2020;323:2139-42. doi: 10.1001/jama.2020.2648 pmid: 32091533

4 National Institute for Health and Care Excellence. COVID-19 rapid guideline: managing suspected or confirmed pneumonia in adults in the community 2020. https://www.nice.org.uk/guidance/ng165/chapter/3-Diagnosis-and-assessment 2020.

5 Public Health England. COVID-19: investigation and initial clinical management of possible cases. 2020. https://www.gov.uk/government/publications/wuhan-novel-coronavirus-initial-investigationof-possible-cases/investigation-and-initial-clinical-management-of-possible-cases-of-wuhannovel-coronavirus-wn-cov-infection.

6 Hansell DM, Bankier AA, MacMahon H, McLoud TC, Müller NL, Remy J. Fleischner Society: glossary of terms for thoracic imaging. Radiology 2008;246:697-722. doi: 10.1148/radiol.2462070712 pmid: 18195376

7 Yoon SH, Lee KH, Kim JY, etal. Chest radiographic and CT findings of the 2019 novel coronavirus disease (COVID-19): analysis of nine patients treated in Korea. Korean J Radiol2020;21:494-500. doi: 10.3348/kjr.2020.0132 pmid: 32100485

8 Hosseiny M, Kooraki S, Gholamrezanezhad A, Reddy S, Myers L. Radiology Perspective of Coronavirus Disease 2019 (COVID-19): Lessons From Severe Acute Respiratory Syndrome and Middle East Respiratory Syndrome. AJR Am J Roentgenol 2020;214:1078-82. doi: 10.2214/AJR.20.22969 pmid: 32108495

9 Pezzotti W. Chest X-ray interpretation: not just black and white. Nursing 2014;444:40-7, quiz 47-8. doi: 10.1097/01.NURSE.0000438704.82227.44 pmid: 24281317

10 Rodriguez-Morales AJ, Cardona-Ospina JA, Gutiérrez-Ocampo E, etalLatin American Network of Coronavirus Disease 2019-COVID-19 Research (LANCOVID-19). Electronic address: https://www.lancovid.org. Clinical, laboratory and imaging features of COVID-19: A systematic review and meta-analysis. Travel Med Infect Dis 2020;34: doi: 10.1016/j.tmaid.2020.101623 pmid: 32179124

11 Wong HYF, Lam HYS, Fong AH-T, etal. Frequency and distribution of chest radiographic findings in covid-19 positive patients. Radiology 2020. doi: 10.1148/radiol.2020201160. pmid: 32216717

12 Jacobi A, Chung M, Bernheim A, Eber C. Portable chest X-ray in coronavirus disease-19 (COVID-19): A pictorial review. Clin Imaging 2020;64:35-42. doi: 10.1016/j.clinimag.2020.04.001 pmid: 32302927

13 Chen N, Zhou M, Dong X, etal. Epidemiological and clinical characteristics of 99 cases of 2019 novel coronavirus pneumonia in Wuhan, China: a descriptive study. Lancet 2020;395:507-13. doi: 10.1016/S0140-6736(20)30211-7 pmid: 32007143

14 Zhao W, Zhong Z, Xie X, Yu Q, Liu J. Relation between chest CT findings and clinical conditions of coronavirus disease (COVID-19) pneumonia: a multicenter study. AJR Am J Roentgenol 2020;214:1072-7. doi: 10.2214/AJR.20.22976 pmid: 32125873

15 Zeng J-HY, Liu Y, Yuan J, et al. Clinical characteristics and cardiac injury description of 419 cases of COVID-19 in Shenzhen, China. SSRN 3556659 [Preprint] 2020. https://ssrn.com/abstract $=3556659$

16 Chen T, Wu D, Chen H, etal. Clinical characteristics of 113 deceased patients with coronavirus disease 2019: retrospective study. BM/2020;368:m1091. doi: 10.1136/bmj.m1091 pmid: 32217556

17 Chen J, Qi T, Liu L, etal. Clinical progression of patients with COVID-19 in Shanghai, China. J Infect 2020;80:e1-6. doi: 10.1016/j.jinf.2020.03.004 pmid: 32171869

18 Zhou F, Yu T, Du R, etal. Clinical course and risk factors for mortality of adult inpatients with COVID-19 in Wuhan, China: a retrospective cohort study. Lancet 2020;395:1054-62. doi: 10.1016/S0140-6736(20)30566-3 pmid: 32171076

19 Nir Paz R. Atypical pneumonia. BMJ Best Pract 2019. https://bestpractice.bmj.com/topics/en$\mathrm{gb} / 18$

20 Franquet T. Imaging of pneumonia: trends and algorithms. Eur Respir /2001;18:196-208. doi: 10.1183/09031936.01.00213501 pmid: 11510793

21 Henry TS, Kligerman SJ, Raptis CA, Mann H, Sechrist JW, Kanne JP. Imaging findings of vaping-associated lung injury. AIR Am J Roentgenol 2020;214:498-505 doi: 10.2214/AJR.19.22251 pmid: 31593518

22 Rubin GD, Ryerson CJ, Haramati LB, etal. The role of chest imaging in patient management during the COVID-19 pandemic: a multinational consensus statement from the Fleischner Society. Radiology 2020;296:172-80. doi: 10.1148/radiol.2020201365 pmid: 32255413

23 Salehi S, Abedi A, Balakrishnan S, Gholamrezanezhad A. Coronavirus disease 2019 (COVID-19): a systematic review of imaging findings in 919 patients. AJR Am J Roentgenol 2020;215:87-93. doi: 10.2214/AJR.20.23034 pmid: 32174129

24 Guan W-J, Ni Z-Y, Yu H, etal. Clinical characteristics of coronavirus disease 2019 in China. N Engl J Med 2020;382:1708-20.

25 Ng M-Y, Lee EYP, Yang J, etal. Imaging profile of the COVID-19 infection: radiologic findings and literature review. Radiol Cardiothor Imag 2020;2:doi: 10.1148/ryct.2020200034.

26 Jones M. NEWSDIG: The National Early Warning Score Development and Implementation Group. Clin Med (Lond) 2012;12:501-3.
27 British Society of Thoracic Imaging. https://www.bsti.org.uk/media/resources/files/NHSE_BSTI_APPROVED_Radiology_on_CoVid19_v6_modified1___Read-Only.pdf2020

28 BMJ Best Practice. Coronavirus disease 2019 (COVID-19) Epidemiology. 2020. https://bestprac tice.bmj.com/topics/en-gb/3000168/epidemiology.

29 National institute for Health and Care Excellence. Coronavirus-COVID 19. Scenario: suspected coronavirus infection. 2020. https://cks.nice.org.uk/coronavirus-covid-19\#!scenario.

30 Greenhalgh T, Koh GCH, Car J. Covid-19: a remote assessment in primary care. BMJ 2020;368:m1182. doi: 10.1136/bmj.m1182 pmid: 32213507

31 British Society of Thoracic Imaging. Updated version 2 BSTI COVID-19 guidance for the reporting radiologist. 2020. https://www.bsti.org.uk/standards-clinical-guidelines/clinical-guidelines/bsticovid-19-guidance-for-the-reporting-radiologist/2020.

32 Klok FA, Kruip MJHA, van der Meer NJM, etallncidence of thrombotic complications in critically ill ICU patients with COVID-19. Thrombosis Res 2020. doi: 101016/ithromres202004013.

33 Simpson S, Kay FU, Abbara S, etal. Radiological Society of North America expert consensus statement on reporting chest CT findings related to COVID-19. Endorsed by the Society of Thoracic Radiology, the American College of Radiology, and RSNA. J Thorac Imaging 2020;35:219-27. doi: 10.1097/RTI.0000000000000524 pmid: 32324653

34 Albarello F, Pianura E, Di Stefano F, etalCOVID 19 INMI Study Group. 2019-novel Coronavirus severe adult respiratory distress syndrome in two cases in Italy: An uncommon radiological presentation. Int J Infect Dis 2020;93:192-7. doi: 10.1016/j.jijid.2020.02.043 pmid: 32112966

35 Rouger M. Imaging the coronavirus disease COVID-19. Healthcare in Europe.Com. 2020. https://healthcare-in-europe.com/en/news/imaging-the-coronavirus-disease-covid-19.html.

36 Borghesi A, Maroldi R. COVID-19 outbreak in Italy: experimental chest X-ray scoring system for quantifying and monitoring disease progression. Radiol Med 2020;125:509-13. doi: 10.1007/s11547-020-01200-3 pmid: 32358689

37 Ayebare RR, Flick R, Okware S, Bodo B, Lamorde M. Adoption of COVID-19 triage strategies for low-income settings. Lancet Respir Med 2020;8:. doi: 10.1016/S2213-2600(20)30114-4 pmid: 32171063

38 Hare S, Jacob J, Johnstone A, Robinson G. Covid-19: is CT scanning ready to answer a diagnostic call? BMJ Opinion 2020. https://blogs.bmj.com/bmj/2020/03/12/covid-19-is-ct-scanning-readyto-answer-a-diagnostic-call/

39 Kooraki S, Hosseiny M, Myers L, Gholamrezanezhad A. Coronavirus (COVID-19) Outbreak: what the department of radiology should know. J Am Coll Radiol 2020;17:447-51.

doi: 10.1016/j.jacr.2020.02.008 pmid: 32092296

40 British Thoracic Society. Guidance on respiratory follow up of patients with a clinic-radiological diagnosis of covid-19 pneumonia. 2020. https://www.brit-thoracic.org.uk/document-library/quality-improvement/covid-19/resp-follow-up-guidance-post-covid-pneumonia/

This article is made freely available for use in accordance with BMJ's website terms and conditions for the duration of the covid-19 pandemic or until otherwise determined by BMJ. You may use, download and print the article for any lawful, non-commercial purpose (including text and data mining) provided that all copyright notices and trade marks are retained. 